\title{
HUBUNGAN ANTARA PENGETAHUAN LINGKUNGAN DENGAN PERILAKU \\ PROLINGKUNGAN SEKOLAH ADIWIYATA \\ (Studi Kasus SDN 21 Taluak Kab. Agam)
}

\author{
MARTINI \\ Fakultas Teknik Universitas Batanghari, Jambi \\ martiniarifin@yahoo.com
}

\begin{abstract}
Absract: The objective of this research is to analyze the relationship of environmental knowledge withpro-environmental behavior in elementary school students (SD). Pro-environmental behavior was analyzed by Lawrence Green's model theory and environmental knowledge was measured using the NEP scale. The results of this study in accordance with Lawrence Green's theory that environmental knowledge is not related to pro-environmental behavior in studentspost Adiwiyata school. Result of analysis of pro-environmental behavior found that the pro environmental behavior of postAdiwiyataschool better. Thus the Adiwiyata program has a positive influence in changing the proenvironment behavior.
\end{abstract}

Keywords: environmental knowledge, environmental behavior, Adiwiyata program

\begin{abstract}
Abstrak: Penelitian bertujuan untuk menganalisis hubungan pengetahuan lingkungan dengan perilaku prolingkungan pada peserta didik sekolah dasar (SD) Adiwiyata. Perilaku prolingkungan dianalisis dengan model teori Lawrence Green dan pengetahuan lingkungan diukur menggunakan skala NEP. Hasil penelitian ini sesuai dengan teori Lawrence Green yakni pengetahuan lingkungan tidak berhubungan dengan perilaku prolingkungan pada peserta didik sekolah Adiwiyata. Hasil analisis perilaku prolingkungan didapatkan bahwa perilaku prolingkungan sekolah Adiwiyata sangat baik. Dengan demikian program Adiwiyata mempunyai pengaruh positif dalam mengubah perilaku prolingkungan.
\end{abstract}

Kata Kunci: pengetahuan lingkungan, perilaku prolingkungan, program Adiwiyata

\section{PENDAHULUAN}

Program Adiwiyata merupakan tindak lanjut dari MoU antara Menteri Negara Lingkungan Hidup dan Menteri Pendidikan Nasional pada tanggal 3 Juni 2005. Program Adiwiyata baru mulai di Pulau Jawa pada tahun 2006 kemudian dilaksanakan menyeluruh ke tiap provinsi di Indonesia sejak tahun 2007 (Kementerian Lingkungan Hidup, 2010). Program Adiwiyata diikuti oleh Sekolah Dasar atau sederajat, Sekolah Menengah Pertama atau sederajat dan Sekolah Menengah Atas atau sederajat. Kegiatan utama program Adiwiyata adalah mewujudkan kelembagaan sekolah yang peduli dan berbudaya lingkungan bagi sekolah dasar dan menengah di Indonesia. Dengan program ini diharapkan dalam setiap perkembangan Ilmu Pengetahuan dan Teknologi selalu dikaji juga bagaimana teknologi tersebut dapat menyeimbangkan daya dukung lingkungan (Kementrian Lingkungan Hidup, 2011).Program Adiwiyata diharapkan dapat mengubah pola pikir generasi terhadap pentingnya keseimbangan lingkungan, sehingga apabila generasi sudah memahami dan mengerti tentang konsep keseimbangan lingkungan,maka besar kemungkinan akan dihasilkan calon-calon pemimpin yang mengerti dan melaksanakan konsep pembangunan berkelanjutan.

Program Adiwiyata merupakan program mendorong terciptanya pengetahuan dan kesadaran pelestarian lingkungan hidup melalui prinsip edukatif, partisipatif dan berkelanjutan. Menurut Badan Lingkungan Hidup Daerah (BLHD) Kabupaten Agam, manfaat program Adiwiyata bagi sekolah dan seluruh warga sekolah diantaranya :

1. Terciptanya lingkungan sekolah yang bersih dan nyaman sehingga dapat meningkatkan prestasi siswa dan seluruh warga sekolah.

2. Mendidik siswa untuk bertanggung jawab terhadap seluruh sarana dan prasarana sekolah sehingga dikemudian hari warga sekolah tersebut dapat ikut bertanggung jawab dalam upaya-upaya 
penyelamatan lingkungan hidup dan pembangunan berkelanjutan.

3. Meningkatkan sensitivitas siswa dan warga sekolah terhadap lingkungan dan tanaman melalui berbagai program dan kebijakan kepala sekolah yang berkaitan dengan cinta lingkungan.

4. Terciptanya kondisi kebersamaan bagi seluruh warga sekolah

5. Terciptanya sekolah sebagai tempat pembelajaran tentang nilai-nilai pemeliharaan dan pengelolaan lingkungan hidup yang baik dan benar serta penyadaran betapa pentingnya menjaga lingkungan.

Menjaga lingkungan tidak dapat dilakukan oleh hanya satu-dua orang atau instansi, tapi oleh semua pihak. Adalah tanggung jawab kita semua untuk memperbaiki dan merubah kondisi lingkungan kita. Oleh karena itu, sangat perlu untuk menanamkan sikap dan karakter peduli dan cinta lingkungan sejak dini terutama kepada generasi muda. Dengan dibekali pengetahuan dan wawasan tentang pentingnya menjaga keselamatan lingkungan, maka generasi muda akan memiliki kesadaran peduli lingkungan yang berujung pada perilaku untuk melestarikan lingkungan.

Menurut Nurjhani dan Widodo (2009), pendidikan lingkungan hidup dibutuhkan dan harus diberikan kepada anak sejak dini agar mereka mengerti dan tidak merusak lingkungan. Pendidikan lingkungan diterapkan dimulai dari Sekolah Dasar (SD). Pendidikan lingkungan hidup di Indonesia telah diupayakan oleh berbagai pihak sejak awal tahun 1970. Selama ini pelaksanaan pendidikan lingkungan hidup dilakukan oleh masing-masing pelaku pendidikan secara terpisah. Salah satunya melalui pendidikan lingkungan hidup program Adiwiyata. Mengingat pentingnya pendidikan lingkungan hidup sebagai suatu upaya untuk meningkatkan pengetahuan, kesadaran, etika, disiplin dan budi pekerti siswa terhadap perilaku prolingkungan hidup salah satunya dengan program Adiwiyata. Program Adiwiyata di Kabupaten Agam sudah dimulai sejak tahun 2011, dimana tim penilai mendatangi sekolah-sekolah yang menjadi peserta program Adiwiyata. Salah satu sekolah yang mendapat penghargaan Adiwiyata adalah
Sekolah Dasar Negeri (SDN) 21 Taluak. Dimulai dengan menjadi sekolah AdiwiyataKabupaten pada tahun 2013, Adiwiyata Nasional pada tahun 2014 dan barubaru ini memperoleh prestasi sebagai sekolah Adiwiyata Mandiri 2016 (Dokumen Adiwiyata Mandiri, 2016).

Lingkungan merupakan ruang yang ditempati suatu makhluk hidup bersama-sama dengan benda hidup dan tak hidup didalamnya (Sumarwoto, 2004). Menurut Undang-Undang No. 32 Tahun 2009 tentang Perlindungan dan Pengelolaan Lingkungan Hidup, lingkungan hidup adalah kesatuan ruang dengan semua benda, daya, keadaan dan mahluk hidup, termasuk manusia dan perilakunya, yang mempengaruhi kelangsungan perikehidupan dan kesejahteraan manusia serta mahluk hidup lain. Antara manusia dan lingkungan hidupnya terdapat hubungan timbal balik. Manusia mempengaruhi lingkungan hidupnya dan sebaliknya manusia dipengaruhi oleh lingkungan hidupnya. Manusia ada didalam lingkungan hidupnya dan ia tidak dapat terpisahkan daripadanya (Sastrawijaya, 2009). Jika lingkungan rusak, maka manusia dalam melakukan aktivitasnya akan terganggu juga.

\section{Pengetahuan Lingkungan}

Pengetahuan atau kognitif merupakan bagian yang penting untuk terbentuknya tindakan seseorang. Perilaku yang didasari oleh pengetahuan, kesadaran dan sikap yang positif, akan lebih lama bertahan daripada perilaku yang tidak didasari oleh pengetahuan (Notoatmodjo, 2007).

Faktor-faktor yang mempengaruhi pengetahuan antara lain:

1) Umur

Umur adalah usia individu yang terhitung mulai saat dilahirkan sampai saat beberapa tahun. Semakin cukup umur tingkat kematangan dan kekuatan seseorang akan lebih matang dalam berfikir dan bekerja dari segi kepercayaan masyarakat yang lebih dewasa akan lebih percaya dari pada orang belum cukup tinggi kedewasaannya. Hal ini sebagai akibat dari pengalaman jiwa (Nursalam, 2001). Singgih D. Gunarso (1990) mengemukakan bahwa makin tua umur seseorang maka proses-proses perkembangan mentalnya bertambah baik, akan tetapi pada umur tertentu bertambahnya proses 
perkembangan ini tidak secepat ketika berusia belasan tahun.

2) Pendidikan

Tingkat pendidikan berarti bimbingan yang diberikan oleh seseorang terhadap perkembangan orang lain menuju ke arah suatu cita-cita tertentu. (Sarwono, 1992, yang dikutip Nursalam, 2001). Pendidikan adalah salah satu usaha untuk mengembangkan kepribadian dan kemampuan didalam dan diluar sekolah dan berlangsung seumur hidup. Dengan pendidikan yang tinggi maka seseorang akan cenderung untuk mendapatkan informasi baik dari orang lain maupun dari media masa, sebaliknya tingkat pendidikan yang kurang akan menghambat perkembangan dan sikap seseorang terhadap nilai-nilai yang baru diperkenalkan (Koentjaraningrat, 1997, dikutip Nursalam, 2001).

3) Pengalaman

Pengalaman merupakan guru yang terbaik (experience is the best teacher), pepatah tersebut bisa diartikan bahwa pengalaman merupakan sumber pengetahuan, atau pengalaman itu merupakan suatu cara untuk memperoleh suatu kebenaran pengetahuan. Oleh sebab itu pengalaman pribadi pun dapat dijadikan sebagai upaya untuk memperoleh pengetahuan. Penelitian yang dilakukan oleh $M c$ Farlanc, $B$ dan $P$. Boxall mendapatkan fakta di lapangan berupa pengetahuan merupakan variabel yang berkorelasi dengan pengetahuan prolingkungan, dan variabel yang berkorelasi dengan pengetahuan lingkungan adalah tingkat pendidikan. Teori tindakan beralasan (Ajzen, 1991), menjelaskan bahwa pengetahuan faktual tentang lingkungan merupakan prasyarat sikap lingkungan seseorang, pengetahuan ini tidak harus berhubungan dengan perilaku prolingkungan karena masih dipengaruhi oleh sikap lingkungan dan keinginan untuk berbuat atau niat. Maloney (1993) menemukan tidak ada hubungan antara pengetahuan dan perilaku lingkungan.

Pengetahuan atau kognitif merupakan bagian yang penting untuk terbentuknya tindakan seseorang. Perilaku yang didasari oleh pengetahuan, kesadaran dan sikap yang positif, akan lebih lama bertahan daripada perilaku yang tidak didasari oleh pengetahuan (Notoatmodjo, 2007).
Faktor-faktor yang pengetahuan antara lain:

4) Pendidikan

Tingkat pendidikan berarti bimbingan yang diberikan oleh seseorang terhadap perkembangan orang lain menuju ke arah suatu cita-cita tertentu. (Sarwono, 1992, yang dikutip Nursalam, 2001). Pendidikan adalah salah satu usaha untuk mengembangkan kepribadian dan kemampuan didalam dan diluar sekolah dan berlangsung seumur hidup. Dengan pendidikan yang tinggi maka seseorang akan cenderung untuk mendapatkan informasi baik dari orang lain maupun dari media masa, sebaliknya tingkat pendidikan yang kurang akan menghambat perkembangan dan sikap seseorang terhadap nilai-nilai yang baru diperkenalkan (Koentjaraningrat, 1997, dikutip Nursalam, 2001).

5) Pengalaman

Pengalaman merupakan guru yang terbaik (experience is the best teacher), pepatah tersebut bisa diartikan bahwa pengalaman merupakan sumber pengetahuan, atau pengalaman itu merupakan suatu cara untuk memperoleh suatu kebenaran pengetahuan. Oleh sebab itu pengalaman pribadi pun dapat dijadikan sebagai upaya untuk memperoleh pengetahuan.

Penelitian yang dilakukan oleh $M c$ Farlanc, B dan P. Boxall mendapatkan fakta di lapangan berupa pengetahuan merupakan variabel yang berkorelasi dengan pengetahuan prolingkungan, dan variabel yang berkorelasi dengan pengetahuan lingkungan adalah tingkat pendidikan. Teori tindakan beralasan (Ajzen, 1991), menjelaskan bahwa pengetahuan faktual tentang lingkungan merupakan prasyarat sikap lingkungan seseorang, pengetahuan ini tidak harus berhubungan dengan perilaku prolingkungan karena masih dipengaruhi oleh sikap lingkungan dan keinginan untuk berbuat atau niat. Maloney (1993) menemukan tidak ada hubungan antara pengetahuan dan perilaku lingkungan.

\section{Teori yang Berkaitan dengan Perilaku}

Lawrence W. Green terkenal sebagai peneliti pendidikan kesehatan. Lawrence Green dan rekan-rekan mengembangkan Precede or Proceed Model, untuk merencanakan program-program pendidikan kesehatan yang lebih mengarah kepada upaya 
mengubah perilaku kesehatan. PrecedeProceed adalah suatu model evaluasi pengembangan program berdasarkan pada ilmu epidemiologi, sosial, ilmu perilaku dan penerapan sistem administratif serta bidang pendidikan.

Menurut teori Precede-Proceed ini Green menganalisis bahwa faktor perilaku sendiri ditentukan oleh 3 (tiga) faktor yaitu (Notoatmodjo, 2003) :

(1) Faktor predisposisi (predisposing factors)

(2) Faktor pendukung (enabling factors)

(3) Faktor penguat (reinforcing factors)

\section{Skala Pengukuran Prolingkungan}

Dunlap dan Van Liere merancang skala Paradigma Baru Lingkungan (NEP), yang diterbitkan pada tahun 1978 telah menjadi acuan yang banyak digunakan pada penelitian pro lingkungan. Selanjutnya NEP direvisi yang disebut New Ecological Paradigma Skala, terdiri dari 15 item pernyataan. Skala ini dirancang oleh seorang sosiolog lingkungan Riley Dunlap dan rekan. Hal ini dirancang untuk mengukur prolingkungan dari kelompok orang dengan menggunakan instrumen survei. Tanggapan untuk 15 pernyataan ini kemudian digunakan untuk ukuran statistik lingkungan. NEP bermula dari gerakan lingkungan AS dari tahun 1960-1970 an, terinspirasi oleh publikasi Spring Diam Rachel Carson. Seorang psikolog sosial berhipotesis bahwa pandangan dunia yang berlaku dari masyarakat disebut Dominan Paradigma Sosial (DSP) untuk mencerminkan kepedulian lingkungan yang lebih besar. Mengembangkan langkah-langkah yang valid dan dapat diandalkan dari pandangan lingkungan dunia akan membantu sarjana lebih memahami perubahan ini dan hubungannya dengan demografi, ekonomi, dan perubahan perilaku di masyarakat.

Di antara berbagai upaya untuk mengukur perubahan tersebut, Riley Dunlap dan rekan-rekannya di Washington State University mengembangkan instrumen yang disebut Paradigma Lingkungan Baru (NEP) pada tahun 1978. Idenya adalah bahwa alat ini bisa mengukur perubahan masyarakat dari DSP kepada pandangan baru dunia yang lebih ramah lingkungan. NEP yang awal memiliki dua belas item pernyataan. NEP awal dikritik

karena beberapa kekurangan, termasuk kurangnya konsistensi internal antara tanggapan individu, kurang korelasi antara skala dan perilaku, bahasa yang digunakan dalam instrumen. Dunlap dan rekan kemudian mengembangkan Skala New Paradigma Ekologis untuk menanggapi kritik dari NEP awal. Skala ini disebut sebagai skala NEP direvisi untuk membedakannya dari skala NEP awal.

NEP revisi memiliki lima belas pernyataan (item). Delapan dari item dimaksudkan untuk mendukung paradigma baru (NEP), sementara tujuh item mendukung DSP. Para peneliti menegaskan bahwa NEP revisi memiliki kekuatan yang membuatnya menjadi alat yang handal dan valid untuk mengukur paradigma masyarakat terhadap lingkungan. Mereka mengatakan skala ini konsisten secara internal dan mewakili ukuran skala tunggal.

Instrumen New Ecological Paradigm (NEP) revisi, dapat dilihat pada tabel dibawah ini :

Tabel 1. Tabel pernyataan NEP revisi

No. Pernyataan

\begin{tabular}{|c|c|}
\hline & Kita mendekati batas jumlah orang \\
\hline & Manusia memiliki hak untuk \\
\hline 3 & memodifikasi lingkungan alam untuk \\
\hline 4 & memenuhi kebutuhannya \\
\hline 5 & Ketika manusia mengganggu alam \\
\hline 6 & itu sering menghasilkan bencana \\
\hline $\begin{array}{l}7 \\
8\end{array}$ & $\begin{array}{ll}\text { Kecerdikan manusia } & \text { akan } \\
\text { memastikan bahwa kami } & \text { tidak } \\
\text { membuat bumi dijalani } & \end{array}$ \\
\hline 9 & $\begin{array}{l}\text { Manusia sering menyalahkan } \\
\text { lingkungan }\end{array}$ \\
\hline 10 & $\begin{array}{l}\text { Bumi memiliki banyak sumber daya } \\
\text { alam jika kita hanya belajar } \\
\text { bagaimana mengembangkannya }\end{array}$ \\
\hline 11 & $\begin{array}{l}\text { Tanaman dan hewan memiliki hak } \\
\text { sebagaimana manusia eksis }\end{array}$ \\
\hline 12 & Keseimbangan alam cukup kuat \\
\hline 13 & untuk mengatasi dampak dari negara- \\
\hline 14 & negara industri modern \\
\hline 15 & $\begin{array}{l}\text { Meskipun kemampuan khusus kami, } \\
\text { manusia masih tunduk pada hukum- } \\
\text { hukum alam }\end{array}$ \\
\hline & $\begin{array}{l}\text { Yang disebut "krisis ekologi" yang } \\
\text { dihadapi umaat manusia telah sangat } \\
\text { dibesar-besarkan Bumi adalah seperti } \\
\text { sebuah pesawat ruang angkasa }\end{array}$ \\
\hline
\end{tabular}




\begin{tabular}{|l|l|}
\hline dengan ruang dan sumber daya yang \\
sangat terbatas \\
Manusia dimaksudkan untuk \\
menguasai seluruh alam \\
Keseimbangan alam sangat halus dan \\
mudah marah \\
Manusia akhirnya akan belajar cukup \\
tentang bagaimana alam bekerja \\
untuk dapat mengendalikannya \\
Jika hal melanjutkan program \\
mereka, kami akan segera mengalami \\
bencana utama ekologi
\end{tabular}

Sumber : Dunlap et al, (2000)

\section{METODOLOGI PENELITIAN}

Metode penelitian yang digunakan untuk penelitian ini adalah metode Kuantitatif Komparatif. Dalam penelitian ini peneliti bermaksud mencari perbandingan perilaku prolingkungan peserta didik ketka berada di sekolah dan di rumah pada 2 (dua) sekolah (SDN 21 Taluak). Penelitian ini menganalisis data berupa angka-angka. Penulis perlu menilai sesuatu yang tidak angka-angka (pengetahuan lingkungan dan perilaku prolingkungan) karena perlu untuk mengukur sesuatu yang disebut variabel secara kuantitatif dan menguji hubungan antar variabel bebas dan variabel terikat secara kuantitatif. Hubungan-hubungan antar variabel diketahui dan ditunjukkan dengan melakukan uji statistik. Salah satu keuntungan utama dari penelitian ini adalah menghasilkan sebaran hal-hal dalam suatu populasi dan signifikan hubungan. Kemudian dari hasil sebaran dan signifikan hubungan penulis membandingkan perilaku prolingkungan peserta didik sekolah Adiwiyata apakah ada perbedaan dengan pengetahuan lingkungan.

\section{Pengujian Validitas dan Reliabilitas}

1. Uji Validitas Instrumen

Instrumen dikatakan valid apabila instrumen tersebut dapat dengan tepat mengukur apa yang hendak diukur. Instrumen yang telah disetujui dicobakan pada sampel minimal 30 orang lapangan. Uji validitas instrumen dari masing-masing variabel dalam penelitian ini dilakukan dengan bantuan program SPSS Versi 16. Pengujian menggunakan program SPSS menghasilkan output yang dapat dilihat pada Lampiran. Dari hasil pengujian diperoleh bahwa seluruh item memiliki nilai koefisien korelasi di atas 0,361(tabel nilai r Product Moment). Artinya apabila $r_{x y}$ lebih besar atau sama dengan 0,361 $\left(r_{x y} \geq 0,361\right)$, instrumen tersebut dapat dikatakan valid.

2. Reliabilitas Instrumen

a. Instrumen yang skor jawabannya hanya dua, yaitu satu (1) dan nol (0) menggunakan metode belah dua oleh Spearman-Brown.

b. Instrumen pengukuran yang bersifat gradual yaitu ada penjenjangan skor, mulai dari skor tertinggi sampai skor terendah (1 sampai 45). Untuk instrumen skor non diskrit ini analisis reliabilitasnya menggunakan rumus Alpha

Uji reliabilitas dalam penelitian ini dilakukan dengan bantuan program SPSS Versi 16. Pengujian menggunakan program SPSS menghasilkan output yang dapat dilihat pada tabel dibawah ini.

Tabel 2. Reliabilitas Item Pernyataan Pengetahuan Lingkungan

\begin{tabular}{lcc}
\hline Spearman- & Equal Length & 0,607 \\
\cline { 2 - 3 } Brown & & 0,607 \\
\hline
\end{tabular}

Tabel 3. Reliabilitas Item Pernyaatan Perilaku Prolingkungan di Sekolah

\begin{tabular}{cl}
\hline Cronbach's Alpha & $\mathrm{N}$ \\
\hline 0,838 & 10 \\
\hline
\end{tabular}

Tabel 4. Reliabilitas item pernyataan perilaku prolingkungan di rumah

\begin{tabular}{cc}
\hline Cronbach's Alpha & $\mathrm{N}$ \\
\hline 0,838 & 8 \\
\hline
\end{tabular}

Untuk mengetahui apakah instrumen tersebut reliabel atau tidak adalah mengkonsultasikan dengan harga kritik atau standar reliabilitas. Harga kritik untuk indeks reliabilitas instrumen adalah 0,6 .

\section{HASIL DAN PEMBAHASAN \\ Skor Pengetahuan Lingkungan}

Skor pengetahuan lingkungan pada sekolah Adiwiyata secara total menunjukkan angka 273 dari 52 responden dengan skor ratarata pengetahuan lingkungan adalah 5,25. Berdasarkan kategori penilaian skor bahwa 
pengetahuan lingkungan peserta didik sekolah Adiwiyata tergolong baik. Seperti telah dijelaskan pada bab sebelumnya program Adiwiyata ini terdiri dari empat komponen yakni kebijakan sekolah, kurikulum, kegiatan dan sarana dan prasarana pendukung. Pada angket test variabel pengetahuan lingkungan bukan mengenai komponen program Adiwiyata melainkan menggunakan skala NEP mengenai daya dukung bumi, bencana alam, ekosistem dan sumberdaya alam. Pengetahuan tentang lingkungan ini sudah tercantum pada bahan ajar mata pelajaran IPA dan IPS kelas IV dan V. Jadi semua peserta didik diberikan pengetahuan yang hampir sama. Antara kedua sekolah memiliki tingkat pengetahuan lingkungan yang sama, dikarenakan kurikulum dan bahan ajar yang digunakan oleh guru kedua sekolah ini sama yakni kurikulum 2013 dan Pusat Perbukuan Departemen Pendidikan Nasional.

\section{Skor Perilaku Prolingkungan di Sekolah}

Skor perilaku prolingkungan di sekolah pada peserta didik sekolah Adiwiyata secara total menunjukkan angka 1.889 dari 52 responden dengan skor rata-rata perilaku prolingkungan di sekolah adalah 36,33. Berdasarkan kategori penilaian skor bahwa perilaku prolingkungan di sekolah peserta didik sekolah Adiwiyata tergolong sangat baik. Skor perilaku prolingkungan di sekolah pada peserta didik sekolah belum Adiwiyata secara total menunjukkan angka 1.687 dari 48 responden dengan skor rata-rata perilaku prolingkungan di sekolah adalah 35,15. Berdasarkan kategori penilaian skor bahwa perilaku prolingkungan di sekolah peserta didik sekolah belum Adiwiyata tergolong sangat baik.

Skor penilaian perilaku prolingkungan di sekolah, sekolah Adiwiyata lebih tinggi $(36,33)$ dibandingkan skor perilaku prolingkungan di sekolah pada peserta didik sekolah belum Adiwiyata $(35,15)$. Hal ini menjelaskan bahwa perilaku prolingkungan peserta didik sekolah Adiwiyata lebih baik dibandingkan dengan perilaku prolingkungan peserta didik sekolah belum Adiwiyata ketika berada di sekolah. Sebagai contoh perilaku prolingkungan dalam penanganan sampah, penanaman pohon, dan perilaku hemat energi, peserta didik sekolah Adiwiyata lebih baik dibandingkan perilaku peserta didik sekolah belum Adiwiyata.

\section{Skor Perilaku Prolingkungan di Sekolah}

Skor perilaku prolingkungan di sekolah pada peserta didik sekolah Adiwiyata secara total menunjukkan angka 1.889 dari 52 responden dengan skor rata-rata perilaku prolingkungan di sekolah adalah 36,33. Berdasarkan kategori penilaian skor bahwa perilaku prolingkungan di sekolah peserta didik sekolah Adiwiyata tergolong sangat baik. Hal ini menjelaskan bahwa perilaku prolingkungan peserta didik sekolah Adiwiyata lebih baik, sebagai contoh perilaku prolingkungan dalam penanganan sampah, penanaman pohon, dan perilaku hemat energi, peserta didik sekolah Adiwiyata sangat baik.

Skor Perilaku Prolingkungan di Rumah

Skor perilaku prolingkungan di rumah pada peserta didik sekolah Adiwiyata secara total menunjukkan angka 1.515 dari 52 responden dengan skor rata-rata perilaku prolingkungan di rumah adalah 29,13. Berdasarkan kategori penilaian skor bahwa perilaku prolingkungan di rumah peserta didik sekolah Adiwiyata tergolong sangat baik. Hal ini menunjukkan bahwa perilaku prolingkungan peserta didik sekolah Adiwiyata ketika berada di rumah seperti perilaku penanganan sampah, penanaman pohon dan hemat energi sangat baik.

\section{Analisis Korelasi}

Untuk mengetahui korelasi atau hubungan antar variabel pengetahuan lingkungan dan variabel perilaku prolingkungan digunakan program SPSS dengan metoda Chi-Square Test dan metode Pearson Product Momen, selanjutnya juga dikaji kekuatan hubungannya.

\section{Pengetahuan Lingkungan dengan Perilaku Prolingkungan di Sekolah}

Tabel 5 menyajikan hubungan antara pengetahuan lingkungan dengan perilaku prolingkungan peserta didik di sekolah.

Tabel 5. Hubungan pengetahuan lingkungan dengan perilaku prolingkungan

\begin{tabular}{|c|c|c|c|c|}
\hline & Nilai & Tempat & $\mathrm{db}$ & Signifikan \\
\hline $\begin{array}{l}\text { Pearson } \\
\text { Chi- } \\
\text { Sayare }\end{array}$ & 56,317 & $\begin{array}{c}\text { Sekolah } \\
\text { Adiwiyata }\end{array}$ & 60 & 0,611 \\
\hline
\end{tabular}

Sumber : Hasil Analisis Data, 2017 
Dari tabel di atas terlihat pada sekolah Adiwiyata, hasil pearson chi square sebesar 56,317. Hasil ini lebih kecil dari nilai chisquare tabel $(90,5)$ untuk derajat kebebasan (db) 60 dengan nilai signifikan 0,611. Artinya pengetahuan lingkungan tidak ada hubungan dengan perilaku prolingkungan di sekolah untuk peserta didik sekolah Adiwiyata. Dari hasil analisis chi-square test, terlihat bahwa tidak ada hubungan antara pengetahuan lingkungan dari peserta didik yang diteliti dengan perilaku prolingkungan di sekolah. Hasil analisisnya adalah tidak terdapat hubungan yang berarti perilaku prolingkungan di sekolah tidak dipengaruhi oleh tingkat pengetahuan lingkungan peserta didik. Pengetahuan lingkungan peserta didik mengenai daya dukung bumi, bencana alam, sumberdaya alam dan keseimbangan alam tidak berkolerasi dengan perilaku prolingkungan seperti memilah dan membuang sampah pada tempatnya, memanfaatkan barang bekas dan daun-daun kering, memelihara tanaman dan hewan dan hemat energi. Peserta didik tingkat sekolah dasar ini memiliki perilaku prolingkungan yang sangat baik, tetapi tidak pengetahuan lingkungannya.

\section{Pengetahuan Lingkungan dengan Perilaku Prolingkungan di Rumah}

Tabel 6 menyajikan hubungan antara pengetahuan lingkungan dengan perilaku prolingkungan peserta didik di rumah.

Tabel 6. Hubungan pengetahuan lingkungan dengan perilaku prolingkungan

\begin{tabular}{lcccc}
\hline & Nilai & Tempat & db & $\begin{array}{c}\text { Signifik } \\
\text { an }\end{array}$ \\
\hline $\begin{array}{l}\text { Pearson } \\
\text { Chi- }\end{array}$ & 85,038 & $\begin{array}{c}\text { Sekolah } \\
\text { Adiwiyata }\end{array}$ & 66 & 0,057
\end{tabular}

Square

Sumber : Hasil Analisis Data, 2017

Dari tabel di atas terlihat pada sekolah Adiwiyata, hasil pearson chi square sebesar 85,038 . Hasil ini lebih kecil dari nilai chisquare tabel $(103,97)$ untuk derajat kebebasan (db) 66 dengan nilai signifikan 0,057. Artinya pengetahuan lingkungan tidakada hubungan dengan perilaku prolingkungan di sekolah untuk peserta didik sekolah Adiwiyata.

Dari hasil analisis chi-square test, terlihat bahwa tidak ada hubungan antara pengetahuan lingkungan dengan perilaku prolingkungan peserta didik ketika berada di rumah. Hasil analisisnya adalah tidak ada hubungan, yang berarti tingkat pengetahuan lingkungan peserta didik tidak berpengaruh terhadap perilaku prolingkungan di rumah.Dari hasil pernyataan dari instrumen pengetahuan lingkungan, peserta didik di sekolah Adiwiyata mempunyai pengetahuan tentang daya dukung bumi, pengetahuan tentang bencana alam, sumberdaya alam dan keseimbangan alam. Pengetahuan lingkungan yang dimiliki peserta didik belum sepenuhnya mengenai program Adiwiyata. Sedangkan perilaku yang dinilai melalui instrumen adalah perilaku prolingkungan dan aktivitas dalam program Adiwiyata. Hal ini menjadi salah satu faktor yang menyebabkan pengetahuan lingkungan peserta didik di sekolah Adiwiyata tidak berhubungan dengan perilaku prolingkungan peserta didik. Hasil penelitian ini sesuai dengan teori Lawrence Green(1980), bahwa pengetahuan tidak langsung berhubungan dengan perilaku karena dipengaruhi oleh niat perilaku lingkungan.

\section{SIMPULAN DAN SARAN Simpulan}

Hasil analisis dan pembahasan dapat diambil kesimpulan sebagai berikut :

1. Pengetahuan lingkungan tidak berhubungan dengan perilaku prolingkungan di sekolah maupun di rumah. Sikap peduli lingkungan dan keinginan untuk berbuat mempunyai hubungan yang kuat dengan perilaku prolingkungan di sekolah maupun perilaku prolingkungan di rumah.

2. Program Adiwiyata mempunyai pengaruh yang positif dalam mengubah perilaku prolingkungan peserta didik.

\section{Saran}

1. Kepala sekolah dan guru-guru mengawasi peserta didik untuk selalu aktif dalam kegiatan prolingkungan agar pengetahuan dan perilaku yang telah diajarkan di sekolah bisa selalu dilakukan ketika berada dimana saja.

2. Sarana dan prasarana pendukung perilaku prolingkungan agar lebih dioptimalkan pemanfaatannya sehingga 
perilaku prolingkungan dapat terjaga kesinambungannya.

3. Bupati dan dinas terkait untuk memperbanyak sekolah Adiwiyata dan memasyarakatkan program Adiwiyata.

\section{DAFTAR PUSTAKA}

Ajzen, I. 1991. The Theory Of Planned Behaviour. Organizational Behaviour And Human Decision Processes. Issue 2

Allport, G.W. 1954. Hand Book of Social Psychology. Cambridge : Addison Wesley. Publishing Company. Inc.

Arikunto, S. 2014. Prosedur Penelitian Suatu Pendekatan Praktik. Edisi VII. Rineka Cipta. Jakarta.

Asari, 2001. Pengukuran pengetahuan sikap dan kepedulian siswa SMA pada lingkungan hidup :Studi kasus: Perbedaan pestasi blajar antara siswa SMA yang mengikuti Pramuka dengan siswa SMA yang tidak mengikuti Pramuka pada tigaSMA di Kota Bekasi. Tesis Ilmu Lingkungan Pascasarjana Universitas Indonesia.

Azhar., M. Djahir Basyir., Alfitri. (2015). Hubungan Pengetahuan dan Etika Lingkungan dengan Sikap dan Perilaku Menjaga Kelestarian Lingkungan. Jurnal Ilmu Lingkungan. Volume 13 Issue 1 : 36-41. Program Studi Ilmu Lingkungan Program Pascasarjana UNDIP.

Bloom Benyamin. 1908. Psikologi Pendidikan. Jakarta

Bettencourt, A. 1989. What is Conctructivism and Why Are They All Talking about it? Michigan State University.

(BLHD) Badan Lingkungan Hidup Daerah Kabupaten Agam. 2016. Profil Adiwiyata Kabupaten Agam.

Bonnes, M and Secchiaroli G. 1995. Environmental Psychology A PsychoSocialIntroduction. Sage Publications. London.

Denison J. 1996. What Is The Difference Between Organizational Culture And Organizational Climate? A Native's Point Of View On A Decate Of ParadigmWars. Academy Of Management Review 21.

Florian G. Kaiser., Sybille W., Urs Fuhrer. 1999. Environmental Attitude andEcological Behaviour. Jurnal of
Environmental Psychology (19), 1-19. http // www. Idealibrary.com.

Glanz, Karen. 2002. Health Behaviour And Health Education. San Fransisco. Jossey Bass.

Green, L. 1980. Health Education Planning A Diagnostic Approach. Baltimore. The John Hopkins University. Mayfield Publishing Co.

Gunarso, S. 1990. Dasar Teori Perkembangan Anak. PT. BPK Gunung Mulia. Jakarta.

Koentjaraningrat. 1997. Metode - Metode Penelitian Masyarakat. Gramedia. Jakarta.

Krech D \& Crutchfield, R. 1962. Individual In Society. Tokyo. McGraw Hill Kogakusha Ltd.

Lorsbach, A \& Tobin, K. 1992. Constructivism as a Referent for Science Teaching. NARST Research Matters - to the Science Teacher, No. 30.

Maloney, T M. 1993. Modern Particleboard And Dry Process Fiberboard Manufactures. Miller Freeman Publications. USA.

Mar'at. 1982. Sikap Manusia, Perubahan Serta Pengukurannya. Jakarta. Ghalia Indonesia.

Mark W. Anderson. 2012. New Ecological Paradigm (NEP) Scale. Berkshire Publishing Group. http // www. Berkshirepublishing. Com.

$\begin{array}{lr}\text { Fakultas Teknik UMSB } & \text { ISSN 2599-2081 } \\ \text { EISSN 2599-2090 }\end{array}$

